\title{
Free Boundary Formulations for two Extended Blasius Problems
}

\author{
Riccardo Fazio ${ }^{1}$ \\ ${ }^{1}$ University of Messina
}

November 4, 2020

\begin{abstract}
In this paper, we have defined the free boundary formulation for two extended Blasius problems. These problems are of interest in boundary layer theory and are deduced from the governing partial differential equations by using appropriate similarity variables. The computed results, for the so-called missing initial condition, are favourably compared with recent results available in the literature.
\end{abstract}

\section{Hosted file}

FBFExBlasius.pdf available at https://authorea.com/users/306625/articles/490760-freeboundary-formulations-for-two-extended-blasius-problems 